\title{
Quantification of bacteria by in vivo bioluminescence imaging in comparison with standard spread plate method and reverse transcription quantitative PCR (RT-qPCR)
}

\author{
Katarína Briestenská ${ }^{1}$ Miriam Mikušová · Karolína Tomčíková · František Kostolanský1 · Eva Varečková ${ }^{1}$ (i)
}

Received: 3 June 2021 / Revised: 3 June 2021 / Accepted: 21 June 2021 / Published online: 29 June 2021

(c) The Author(s) 2021

\begin{abstract}
In vivo bioluminescence imaging (BLI) offers a unique opportunity to analyze ongoing bacterial infections qualitatively and quantitatively in intact animals over time, leading to a reduction in the number of animals needed for a study. Since accurate determination of the bacterial burden plays an essential role in microbiological research, the present study aimed to evaluate the ability to quantify bacteria by non-invasive BLI technique in comparison to standard spread plate method and reverse transcription quantitative PCR (RT-qPCR). For this purpose, BALB/c mice were intranasally infected with $1 \times 10^{5} \mathrm{CFU}$ of bioluminescent Streptococcus pneumoniae A66.1. At day 1 post-infection, the presence of S. pneumoniae in lungs was demonstrated by spread plate method and RT-qPCR, but not by in vivo BLI. However, on the second day p.i., the bioluminescent signal was already detectable, and the photon flux values positively correlated with CFU counts and RT-qPCR data within days 2-6. Though in vivo BLI is valuable research tool allowing the continuous monitoring and quantification of pneumococcal infection in living mice, it should be kept in mind that early in the infection, depending on the infective dose, the bioluminescent signal may be below the detection limit.
\end{abstract}

Keywords Streptococcus pneumoniae $\cdot$ Mouse model $\cdot$ Spread plate method $\cdot$ RT-qPCR $\cdot$ In vivo bioluminescence imaging $\cdot$ Correlation

\section{Introduction}

Streptococcus pneumoniae, also known as pneumococcus, is a leading cause of community-acquired pneumonia and accounts for significant morbidity and mortality worldwide (Brooks and Mias 2018; Torres et al. 2018; Feldman and Anderson 2020). As an opportunistic pathogen, S. pneumoniae colonizes mucosal surfaces of the upper respiratory tract (URT) in humans. Although this colonization is usually asymptomatic in healthy individuals, it marks the first step in the development of invasive pneumococcal disease. The transition from asymptomatic colonization to disease is highly associated with preceding or concomitant

Communicated by Erko Stackebrandt.

Eva Varečková

viruevar@savba.sk

1 Biomedical Research Center of the Slovak Academy of Sciences, Institute of Virology, Dúbravská cesta 9, 84505 Bratislava, Slovakia respiratory viral infections, especially influenza, and pneumococcal ability to evade the early components of the host immune response. Changes in the URT microenvironment and inflammation trigger S. pneumoniae dissemination to the middle ear cavity (causing otitis media), the lower respiratory tract (causing pneumonia), the bloodstream (causing sepsis) and/or the meninges (causing meningitis) (Kadioglu et al. 2008; Short et al. 2012; Marks et al. 2013; McCullers 2014; Chao et al. 2015; Weiser et al. 2018).

A mouse model of pneumococcal pneumonia (Chiavolini et al. 2008; Borsa et al. 2019) was utilized to clarify mechanisms of pneumococcal pathogenesis and to assess the efficacy of novel antibiotics and vaccines, as well as to study various aspects of pathogenesis of dual infection with influenza virus and S. pneumoniae (McCullers and Webster 2001; McCullers and Rehg 2002). However, it is essential not only to use a suitable animal model, but also to select the appropriate assessment method (or combination of methods). Therefore, the aim of the present study was to evaluate the pneumococcal infection in mice using different methods: the standard culture-based method (spread plate method), 
the molecular biology technique (reverse transcription quantitative PCR; RT-qPCR) and the non-invasive imaging method (in vivo bioluminescence imaging). The ability to quantify bacteria by these methods was compared.

\section{Materials and methods}

\section{Bacterial strain and growth conditions}

S. pneumoniae A66.1 (serotype 3) bearing the lux transposon cassette, Tn4001 luxABCDE $\left(\mathrm{Km}^{\mathrm{r}}\right)$, was provided by Dr. Jonathan A. McCullers from St. Jude Children's Research Hospital (Memphis, TN, USA). S. pneumoniae bacteria were grown to mid-log phase $\left(\mathrm{OD}_{600}=0.6\right)$ in Todd-Hewitt broth (Sigma Aldrich) containing $400 \mu \mathrm{g} / \mathrm{mL}$ kanamycin (AppliChem) at $37{ }^{\circ} \mathrm{C}$ and $5 \% \mathrm{CO}_{2}$ without shaking. Titer $(\mathrm{CFU} / \mathrm{mL})$ of $S$. pneumoniae was determined by spread plate method on nutrient agar no. 2 (Sigma Aldrich) supplemented with $10 \%$ defibrinated sheep blood and $400 \mu \mathrm{g} / \mathrm{mL}$ kanamycin (AppliChem).

\section{Mice and infection}

Six- to eight-week-old female BALB/c mice $(n=15)$ purchased from the Faculty of Medicine of the Masaryk University (Brno, Czech Republic) were used in this study. Animals were treated according to the standards of the European Union and State Veterinary and Food Administration of the Slovak Republic (SVFA SR). Fundamental ethical principles including animal welfare requirements were respected. All experimental procedures were approved by the SVFA SR before the study was begun (permission number 3932/17221). Mice were anesthetized with isoflurane using the XGI-8 Gas Anesthesia System (PerkinElmer) and inoculated intranasally with $40 \mu \mathrm{l}$ of phosphate-buffered saline (PBS) containing $1 \times 10^{5} \mathrm{CFU}$ of bioluminescent $S$. pneumoniae. Mice were weighed and monitored daily for signs of disease.

\section{In vivo bioluminescence imaging (BLI)}

On days 1, 2, 3, 6 and 9 post-infection (dpi), mice ( $n=3$ per interval) were anesthetized with isoflurane using the XGI-8 Gas Anesthesia System (PerkinElmer) and imaged in dorsal and ventral positions using the IVIS ${ }^{\circledR}$ SpectrumCT In Vivo Imaging System (PerkinElmer). For image acquisition and analysis of bioluminescent signal, Living Image software (version 4.5.5; PerkinElmer) was used. As recommended in Living Image software user's manual, minimum value for counts was set to 600 to ensure signal that is well above the noise.

\section{Determination of bacterial titers in lungs}

Immediately after in vivo BLI, mice were euthanized by cervical dislocation under deep tiletamine/zolazepam anesthesia and lungs were aseptically harvested and washed two times in PBS. Lungs were weighed and promptly homogenized in cold PBS using $\mathrm{T} 10$ basic ULTRA-TURRAX ${ }^{\circledR}$ homogenizer (IKA) to achieve $20 \%$ homogenates. Lung homogenates were pelleted at $1000 \times g$ for 5 min at $4{ }^{\circ} \mathrm{C}$. To determine the bacterial titers in lungs (CFU/mg of tissue), the samples were serially diluted tenfold and plated on nutrient agar no. 2 (Sigma Aldrich) supplemented with $10 \%$ defibrinated sheep blood and $400 \mu \mathrm{g} /$ $\mathrm{mL}$ kanamycin (AppliChem). Plates were incubated at $37{ }^{\circ} \mathrm{C}$ in a $5 \% \mathrm{CO}_{2}$ humidified atmosphere for $24 \mathrm{~h}$. Bioluminescence of grown colonies was verified using the IVIS system.

\section{Two-step RT-qPCR}

Total RNA was isolated from $200 \mu \mathrm{l}$ of lung homogenate supernatants using TRI Reagent ${ }^{\mathrm{TM}}$ Solution (Invitrogen) according to the standard protocol. RNA pellets were resuspended in $30 \mu \mathrm{l}$ of DEPC-treated water (Ambion). The quantity and quality of RNA samples were assessed by NanoDrop 2000c Spectrophotometer (Thermo Scientific). Subsequently, $2 \mu \mathrm{g}$ of total RNA was reverse transcribed in a $20 \mu \mathrm{l}$ reaction volume using the RevertAid First Strand cDNA Synthesis Kit (Thermo Scientific) following the manufacturer's instructions. The resulting cDNA was diluted fivefold in nuclease-free water. Then, mouse $\beta$-actin was amplified as an internal control. Thus, verified cDNA was used as a template in qPCR with primers specific for the $\alpha$ subunit of luciferase gene (luxA) (Fw: 5'-GCATATTTACTTGGCGCG ACT-3'; Rev: 5'-TGCGCCACCTCTGCTATAC-3'). qPCR amplification was performed on a StepOnePlus ${ }^{\mathrm{TM}}$ Real-Time PCR System (Applied Biosystems) using Maxima SYBR Green/ROX qPCR Master Mix (Thermo Scientific) according to the manufacturer's instructions. qPCR reactions contained $3 \mu \mathrm{l}$ of cDNA as a template. qPCR standard curve was generated using tenfold serial dilutions of the standard $-10^{7}-10^{1}$ copies were used as templates in qPCR mixtures. The amplification conditions were as follows: $10 \mathrm{~min}$ at $95{ }^{\circ} \mathrm{C}, 40$ cycles of $15 \mathrm{~s}$ at $95^{\circ} \mathrm{C}$ and $1 \mathrm{~min}$ at $60^{\circ} \mathrm{C}$. The results were analyzed using StepOne software (version 2.3; Applied Biosystems).

\section{Statistical analysis}

Correlation between methods was calculated as Pearson's correlation coefficient $r$ along with $\mathrm{R}$ square and $p$ value 
(two-tailed). The statistics and graphs were made using the software Prism 7 (GraphPad Software Inc.).

\section{Results}

The aim of this study was to compare the ability to quantify bacteria by three different techniques during the course of infection with bioluminescent $S$. pneumoniae in BALB/c mice. At 1 dpi, mice intranasally infected with $1 \times 10^{5} \mathrm{CFU}$ of $S$. pneumoniae did not show any signs of infection and no signal was detected in mice by in vivo BLI (Fig. 1A). However, viable bacteria were recovered from lung tissue samples even at $1 \mathrm{dpi}$ (Fig. 1B). These samples were also found to be positive by two-step RT-qPCR targeting luxA gene (Fig. 1B). At 2 dpi, mild symptoms of disease, such as ruffled fur and shivering, were observed in mice. Bioluminescent images were characterized by strong signals from the thorax but no other anatomical locations in two of three mice (Fig. 1A). Photon flux (photons per sec) was then quantified from selected and defined areas within the ventral images of each mouse (as described in Francis et al. 2001) and the results are presented in Fig. 1B. These observations suggested that only two mice had an established pneumococcal lung infection even though all three mice were infected with the same dose of $S$. pneumoniae. In the lungs of mouse with no evident luminescent signal, the presence of bioluminescent $S$. pneumoniae was proved by spread plate method and RT-qPCR, but bacterial burden and expression level of luxA (Fig. 1B) was lower compared to other two mice. The interindividual variability among mice indicated differences among mice to cope with infection. At $3 \mathrm{dpi}$, the bacterial

(A)
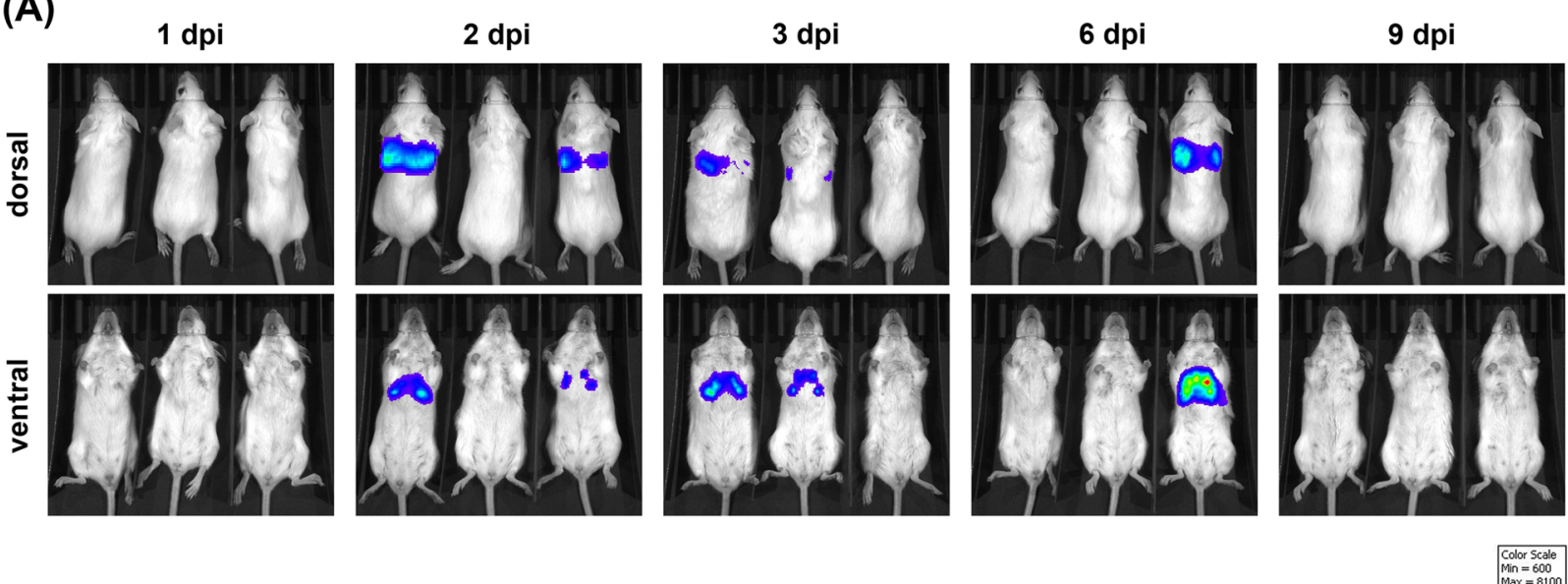

(B)

Number of viable bacteria

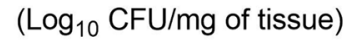

口
Bioluminescence intensity
$\left(\log _{10} \mathrm{p} \cdot \mathrm{s}^{-1} / \mathrm{mg}\right.$ of tissue $)$
IuxA gene expression

$\left(\log _{10}\right.$ RNA copies/mg of tissue $)$

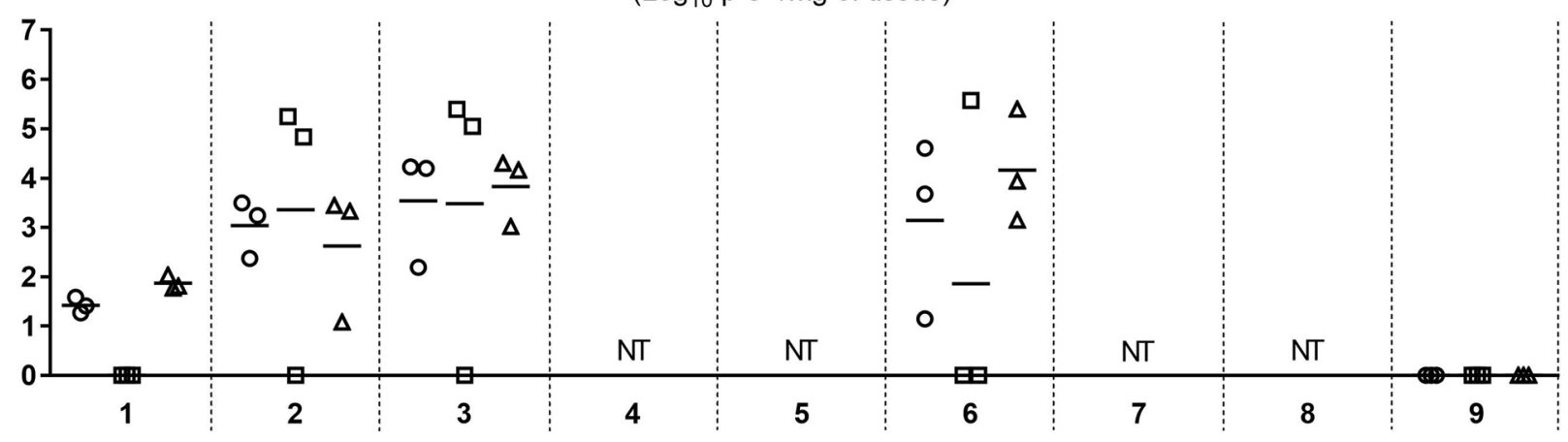

Days post infection

Fig. 1 Evaluation of pneumococcal infection in mice using different methods. BALB/c mice were intranasally infected with $1 \times 10^{5} \mathrm{CFU}$ of bioluminescent $S$. pneumoniae A66.1. At indicated days postinfection $(1,2,3,6$ and 9 dpi), A mice $(n=3)$ were imaged by the IVIS $^{\circledR}$ SpectrumCT In Vivo Imaging System (PerkinElmer) and $\mathbf{B}$ photon flux was quantified from bioluminescent images. Immediately after in vivo imaging, mice were euthanized and lungs were collected. Bacterial titers in lungs were determined by inoculation of samples onto the sheep blood agar plates. Expression of luxA gene in the lungs was analyzed by RT-qPCR. Each symbol represents a value from an individual mouse and the bars indicate average values. $N T$ not tested 
titers in lungs reached peak (mean $=3.54 \log _{10} \mathrm{CFU} / \mathrm{mg}$ of tissue, $\mathrm{SD}=1.17 \log _{10} \mathrm{CFU} / \mathrm{mg}$ of tissue) (Fig. 1B) and mice developed severe clinical symptoms, including hunched posture, decreased activity, and labored breathing. Moreover, macroscopic examination of lungs revealed some areas of hemorrhage. These findings were consistent with BLI results as the strong signals were seen in the lungs of two mice (Fig. 1A, B). Similar to the previous time point ( $2 \mathrm{dpi})$, the mouse that showed no bioluminescent signal at $3 \mathrm{dpi}$ was the one with the lowest bacterial burden in the lungs. At 6 dpi, one mouse had no obvious signs of disease and only minimal pathological changes macroscopically visible in the lungs. The other two mice exhibited serious disease symptoms. These two sick mice had high bacterial titers and high levels of luxA expression (Fig. 1B) in the lungs. Surprisingly, bioluminescent image (Fig. 1A) displayed severe pneumonia only in one mouse. On gross examination, the lungs of mouse with robust bioluminescent signal were highly edematous and hemorrhagic, while the lungs of the other mouse were heavy, gray discolored and filled with mucus. Therefore, we hypothesize that mucus accumulated in the lungs could cause the inhibition of the bioluminescent signal. At 9 dpi, all three mice appeared healthy with normal activity, behavior, and texture of the fur. Lung samples from these mice were tested negative for $S$. pneumoniae by all methods used (Fig. 1B).

The data on S. pneumoniae in lung samples obtained by different methods were plotted against each other and the Pearson's correlation coefficient $(r)$ was calculated. Despite some differences in positivity of infection determined by spread plate method and in vivo BLI and variability of data obtained from individual mice at each time point, the overall correlation between these methods was strongly positive $(r=0.90 ; p \leq 0.0001)$. Results of the Pearson's correlation test for other method pairs (spread plate method vs. RTqPCR, in vivo BLI vs. RT-qPCR) are presented in Table 1.

\section{Discussion}

Culture-based and molecular biology techniques are widely used for the quantification of bacteria. However, both techniques suffer from a number of disadvantages. One of them is day-to-day variability in bacterial counts associated with random selection and killing of mice (Ogunniyi et al. 2018). This could be eliminated by the imaging of bioluminescent reporter bacteria in living mice using a cooled charge-coupled device (CCD) camera. The bioluminescence intensity is proportional to the microbial concentration; therefore, in vivo BLI can be used not only for qualitative but also for quantitative analysis. This technique allows for non-invasive real-time monitoring of infection and tracking of disease progression in an individual animal over time without the need of serial killing of animals, thus the number of research animals is reduced. Moreover, sites of infection not easily sampled by dissection (such as the middle ear) can be visualized and previously overlooked sites can be potentially revealed (Short et al. 2011; Warawa and Lawrenz 2014; Avci et al. 2018).

Our study aimed to determine the bacterial burden in lungs of mice infected with bioluminescent pneumococci using conventional spread plate method, RT-qPCR and in vivo BLI, and to compare quantification capabilities of these methods. Moreover, the Pearson's correlation test was performed for each assay pair (Table 1). Francis et al. (2001) also evaluated bioluminescent S. pneumoniae A66.1 infection in a mouse pneumococcal lung model using in vivo imaging technique. They detected a strong bioluminescent signal from the thorax of mice as early as $20 \mathrm{~h}$ post-infection. However, the design of study by Francis et al. was different from ours-they used higher inoculum dose (approximately $1 \times 10^{6} \mathrm{PFU}$ in $20 \mu \mathrm{l}$ per mouse), they introduced pneumococci into the lungs of BALB/c mice by intratracheal inoculation using a ball-tipped gavage needle, and they monitored bioluminescent infection only for $48 \mathrm{~h}$ (Francis et al. 2001). We used tenfold lower dose of inoculum to induce morbidity but not mortality in mice so that we could monitor the course of infection over longer period of time (9 dpi). In addition, pneumococci were administered into the nostrils of mice in $40 \mu \mathrm{l}$ of PBS. In our study, the presence of $S$. pneumoniae in lungs of mice at $1 \mathrm{dpi}$ was demonstrated by spread plate method and RT-qPCR targeting luxA gene. In vivo BLI, however, failed to detect early pneumococcal infection (1 dpi), which could be due to the lower inoculum dose and the "dilution effect" of intranasally administered bacteria within the respiratory tract, making them undetectable by BLI (Henken et al. 2010). Furthermore, various biophysical parameters and factors have been

Table 1 Correlation between data on $S$. pneumoniae in mouse lungs determined by different methods—spread plate method (viable bacterial count), in vivo bioluminescence imaging (bioluminescent signal) and RT-qPCR (luxA expression)

\begin{tabular}{llll}
\hline & Pearson's correlation coefficient $r$ & $r^{2}$ & Significance, $p$ \\
\hline Viable bacterial count vs. bioluminescent signal & 0.90 & 0.81 & $\leq 0.0001$ \\
Viable bacterial count vs. luxA expression & 0.91 & 0.82 & $\leq 0.0001$ \\
luxA expression vs. bioluminescent signal & 0.78 & 0.61 & $\leq 0.01$ \\
\hline
\end{tabular}


described to affect the sensitivity of BLI, including mouse fur, tissue pigmentation, vascularization and depth from the surface (Badr 2014; Troy et al. 2004; Zinn et al. 2008). If necessary, the sensitivity of BLI method can be increased by imaging excised target organs ex vivo (Henken et al. 2010; Gabrielli et al. 2015). However, ex vivo imaging is invasive and does not allow repetitive assessments of an individual animal (Inoue et al. 2006).

At later time points (2-6 dpi) in our experiment, when the bacteria grew to such an extent that the bioluminescent signal was detectable, the photon flux values strongly correlated with bacterial titers (determined by spread plate method) and the number of RNA copies (determined by RT-qPCR) in lungs of mice.

Taken together, in vivo BLI represents a valuable research tool for qualitative and quantitative monitoring of longterm pneumococcal infections non-invasively in living mice. However, it should be kept in mind that early in the infection, the bioluminescent signal may be below the detection limit. In such cases, additional techniques such as RT-qPCR should be considered to examine the presence of bacteria in tissues.

Acknowledgements The authors thank Dr. Jonathan A. McCullers from St. Jude Children's Research Hospital (Memphis, TN, USA) for kindly providing bioluminescent $S$. pneumoniae A66.1. The authors would also like to thank Margita Mišovičová for skilled technical assistance.

Funding This work was supported by research Grants APVV-17-0445 (EV) from Slovak Research and Development Agency of the Slovak Republic, VEGA No. 2/0048/19 (EV) and VEGA No. 2/0090/21 (KT) from Scientific Grant Agency of the Ministry of Education, Science, Research and Sport of Slovak Republic and Slovak Academy of Sciences.

\section{Declarations}

Conflict of interest None declared.

Open Access This article is licensed under a Creative Commons Attribution 4.0 International License, which permits use, sharing, adaptation, distribution and reproduction in any medium or format, as long as you give appropriate credit to the original author(s) and the source, provide a link to the Creative Commons licence, and indicate if changes were made. The images or other third party material in this article are included in the article's Creative Commons licence, unless indicated otherwise in a credit line to the material. If material is not included in the article's Creative Commons licence and your intended use is not permitted by statutory regulation or exceeds the permitted use, you will need to obtain permission directly from the copyright holder. To view a copy of this licence, visit http://creativecommons.org/licenses/by/4.0/.

\section{References}

Avci P, Karimi M, Sadasivam M, Antunes-Melo WC, Carrasco E, Hamblin MR (2018) In-vivo monitoring of infectious diseases in living animals using bioluminescence imaging. Virulence 9:2863. https://doi.org/10.1080/21505594.2017.1371897

Badr CE (2014) Bioluminescence imaging: basics and practical limitations. Methods Mol Biol 1098:1-18. https://doi.org/10.1007/ 978-1-62703-718-1_1

Borsa N, Di Pasquale M, Restrepo MI (2019) Animal models of pneumococcal pneumonia. Int J Mol Sci 20:4220. https://doi.org/10. 3390/ijms20174220

Brooks LRK, Mias GI (2018) Streptococcus pneumoniae's virulence and host immunity: aging, diagnostics, and prevention. Front Immunol 9:1366. https://doi.org/10.3389/fimmu.2018.01366

Chao Y, Marks LR, Pettigrew MM, Hakansson AP (2015) Streptococcus pneumoniae biofilm formation and dispersion during colonization and disease. Front Cell Infect Microbiol 4:194. https://doi. org/10.3389/fcimb.2014.00194

Chiavolini D, Pozzi G, Ricci S (2008) Animal models of Streptococcus pneumoniae disease. Clin Microbiol Rev 21:666-685. https://doi. org/10.1128/CMR.00012-08

Feldman C, Anderson R (2020) Recent advances in the epidemiology and prevention of Streptococcus pneumoniae infections. F1000Res 9:338. https://doi.org/10.12688/f1000research.22341.1

Francis KP, Yu J, Bellinger-Kawahara C, Joh D, Hawkinson MJ, Xiao G, Purchio TF, Caparon MG, Lipsitch M, Contag PR (2001) Visualizing pneumococcal infections in the lungs of live mice using bioluminescent Streptococcus pneumoniae transformed with a novel gram-positive lux transposon. Infect Immun 69:3350-3358. https://doi.org/10.1128/IAI.69.5.3350-3358.2001

Gabrielli E, Roselletti E, Luciano E, Sabbatini S, Mosci P, Pericolini E (2015) Comparison between bioluminescence imaging technique and CFU count for the study of oropharyngeal candidiasis in mice. Cytometry A 87:428-436. https://doi.org/10.1002/cyto.a.22666

Henken S, Bohling J, Ogunniyi AD, Paton JC, Salisbury VC, Welte T, Maus UA (2010) Evaluation of biophotonic imaging to estimate bacterial burden in mice infected with highly virulent compared to less virulent Streptococcus pneumoniae serotypes. Antimicrob Agents Chemother 54:3155-3160. https://doi.org/10.1128/AAC. 00310-10

Inoue Y, Izawa K, Tojo A, Sekine R, Okubo T, Ohtomo K (2006) Light emission requires exposure to the atmosphere in ex vivo bioluminescence imaging. Mol Imaging 5:53-56. https://doi.org/ 10.2310/7290.2006.00015

Kadioglu A, Weiser JN, Paton JC, Andrew PW (2008) The role of Streptococcus pneumoniae virulence factors in host respiratory colonization and disease. Nat Rev Microbiol 6:288-301. https:// doi.org/10.1038/nrmicro1871

Marks LR, Davidson BA, Knight PR, Hakansson AP (2013) Interkingdom signaling induces Streptococcus pneumoniae biofilm dispersion and transition from asymptomatic colonization to disease. Mbio. https://doi.org/10.1128/mBio.00438-13

McCullers JA (2014) The co-pathogenesis of influenza viruses with bacteria in the lung. Nat Rev Microbiol 12:252-262. https://doi. org/10.1038/nrmicro3231

McCullers JA, Rehg JE (2002) Lethal synergism between influenza virus and streptococcus pneumoniae: characterization of a mouse model and the role of platelet-activating factor receptor. J Infect Dis 186:341-350. https://doi.org/10.1086/341462

McCullers JA, Webster RG (2001) A mouse model of dual infection with influenza virus and Streptococcus pneumoniae. Int Congr Ser 1219:601-607. https://doi.org/10.1016/S0531-5131(01)00631-8

Ogunniyi AD, Kopecki Z, Hickey EE, Khazandi M, Peel E, Belov K, Boileau A, Garg S, Venter H, Chan WY, Hill PB, Page SW, Cowin 
AJ, Trott DJ (2018) Bioluminescent murine models of bacterial sepsis and scald wound infections for antimicrobial efficacy testing. PLoS ONE 13:e0200195. https://doi.org/10.1371/journal. pone.0200195

Short KR, Diavatopoulos DA, Reading PC, Brown LE, Rogers KL, Strugnell RA, Wijburg OLC (2011) Using bioluminescent imaging to investigate synergism between Streptococcus pneumoniae and influenza A virus in infant mice. J vis Exp 50:2357. https:// doi.org/10.3791/2357

Short KR, Habets MN, Hermans PWM, Diavatopoulos DA (2012) Interactions between Streptococcus pneumoniae and influenza virus: a mutually beneficial relationship? Future Microbiol 7:609 624. https://doi.org/10.2217/fmb.12.29

Torres A, Cillóniz C, Blasi F, Chalmers JD, Gaillat J, Dartois N, Schmitt H-J, Welte T (2018) Burden of pneumococcal community-acquired pneumonia in adults across Europe: a literature review. Respir Med 137:6-13. https://doi.org/10.1016/j.rmed. 2018.02.007

Troy T, Jekic-McMullen D, Sambucetti L, Rice B (2004) Quantitative comparison of the sensitivity of detection of fluorescent and bioluminescent reporters in animal models. Mol Imaging 3:9-23. https://doi.org/10.1162/15353500200403196

Warawa JM, Lawrenz MB (2014) Bioluminescent imaging of bacteria during mouse infection. Methods Mol Biol 1098:169-181. https:// doi.org/10.1007/978-1-62703-718-1_14

Weiser JN, Ferreira DM, Paton JC (2018) Streptococcus pneumoniae: transmission, colonization and invasion. Nat Rev Microbiol 16:355-367. https://doi.org/10.1038/s41579-018-0001-8

Zinn KR, Chaudhuri TR, Szafran AA, O'Quinn D, Weaver C, Dugger K, Lamar D, Kesterson RA, Wang X, Frank SJ (2008) Noninvasive bioluminescence imaging in small animals. ILAR J 49:103115. https://doi.org/10.1093/ilar.49.1.103

Publisher's Note Springer Nature remains neutral with regard to jurisdictional claims in published maps and institutional affiliations. 